\title{
Prediction of Pushback Times and Ramp Taxi Times for Departures at Charlotte Airport
}

Hanbong Lee, William J. Coupe, and Yoon C. Jung (NASA Ames Research Center)

\author{
2019 AIAA AVIATION Forum \\ June 17-21, 2019 \\ Hilton Anatole, Dallas, Texas
}


- Introduction

- Data analysis

- Pushback time

- Ramp taxi time

- Data-driven prediction models

- Evaluation using machine learning algorithms

- Conclusions 


\section{Taxi-Out Time of Departures}

- Taxi-out time prediction

- Require to obtain takeoff time input for runway scheduling

- Have focused on total taxi time prediction from gate to runway

- Taxi-out time calculation

Taxi-out time $=$ Pushback time + Ramp transit time + AMA transit time
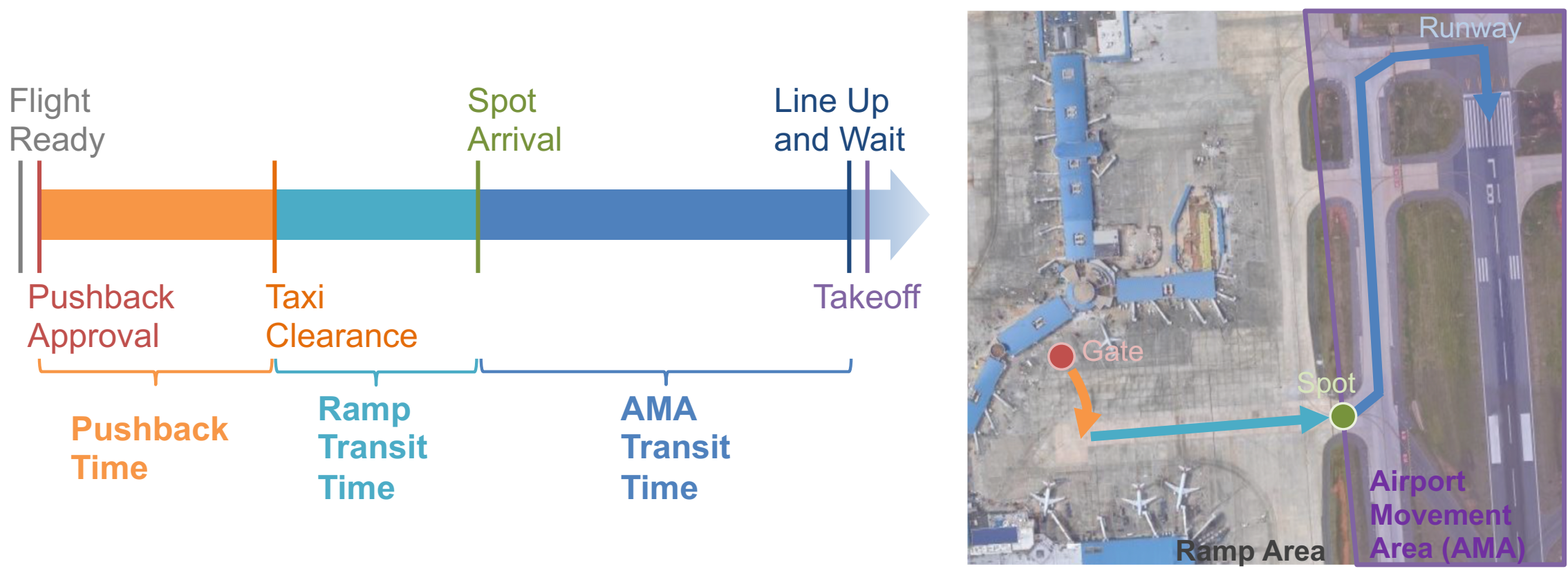

$>$ Lack of accurate data for pushback time and ramp transit time 
- Airspace Technology Demonstration 2 (ATD-2) project

- For the integrated arrival, departure, and surface traffic management capabilities

- Deployed the ATD-2 systems at Charlotte airport in 2017

- Ramp controller input data available since 10/2017

- Through Ramp Traffic Console (RTC)

- Manual input for pushback approval and taxi clearance
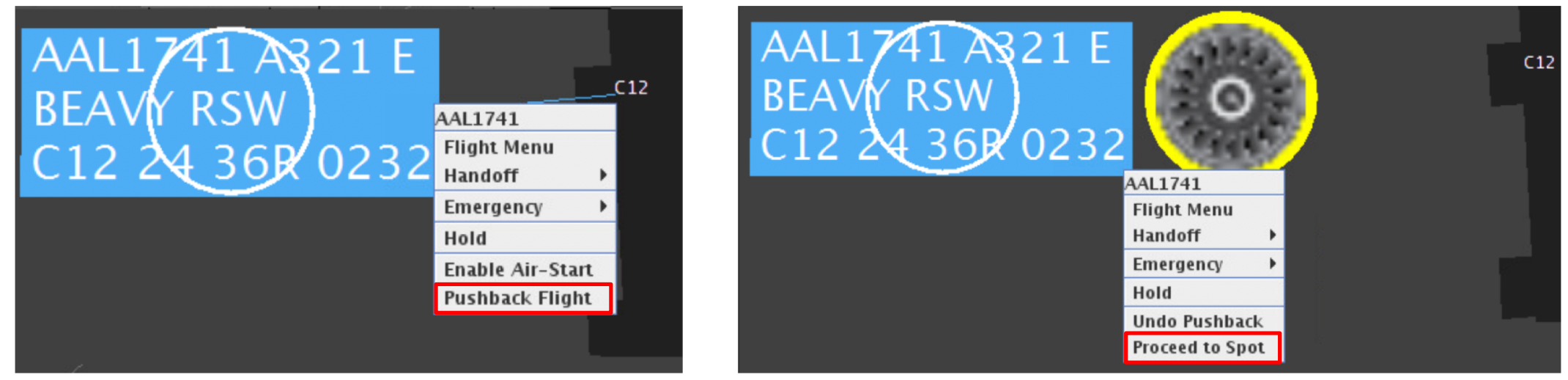

$>$ Can obtain accurate pushback time and ramp taxi time, which can be used for taxi time prediction 


\section{ATDD}

Pushback Time and Ramp Taxi Time Data Analysis for Charlotte Airport (CLT) 
- Actual flight data used for prediction and evaluation

- One-month data at CLT: 8/1/2018 8/31/2018

- 24,642 departures and 24,962 arrivals

- Data filtering

\section{Departures only actual pushback times and spot times}

\section{Ramp controller input_ pushback approval and taxi clearance}

\section{Valid flight state no canceled/return to gate/suspended/unknown}

Valid time value $-30 \mathrm{sec}<=$ pushback or ramp transit time $<1 \mathrm{hr}$

$>$ After data filtering,

we have 20,595 departures (83.6\%) for pushback time analysis and 21,093 departures (85.6\%) for ramp transit time analysis 
- Pushback processes include pushback by tug, engines spooling, communication delay between pilot and ground crew, and so on

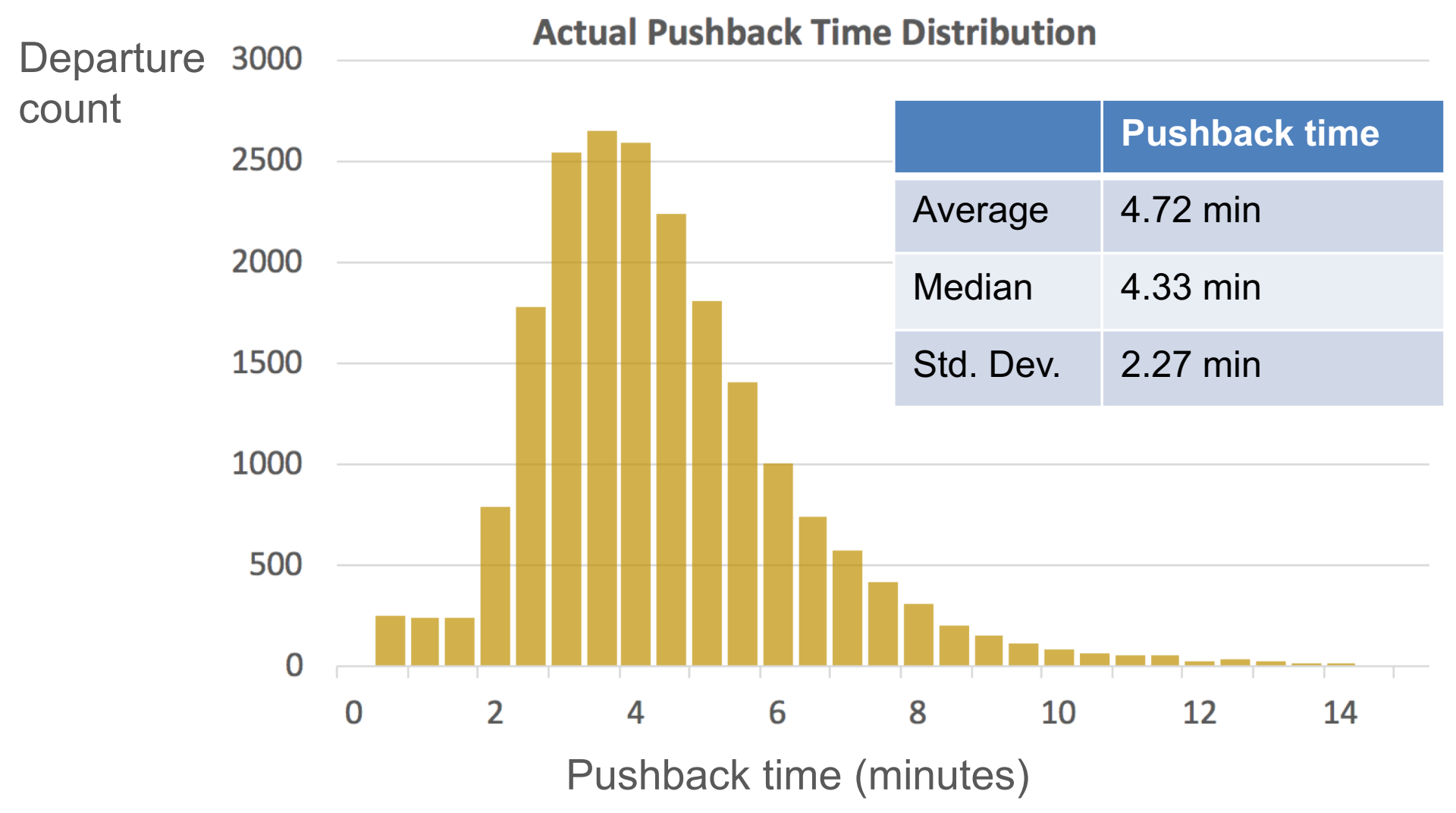




\section{ATD2 Pushback Time Variations by Aircraft Type NASA}

- Pushback times vary, mainly depending on aircraft type and ramp area (gate groups)

Average Pushback Time by Aircraft Type (minutes)

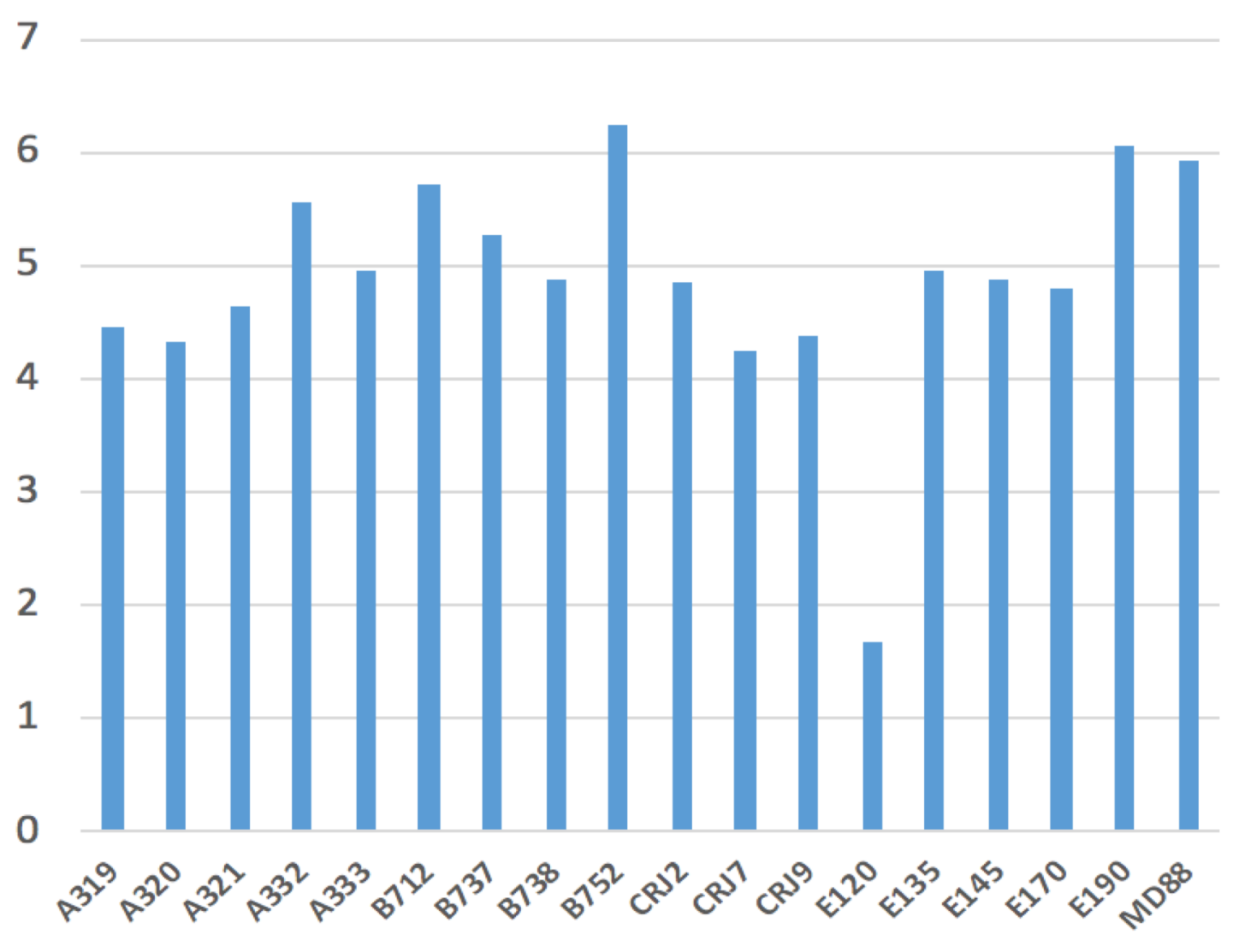




\section{ATD2 Pushback Time Variations by Ramp Area NASA}

- Pushback times vary, mainly depending on aircraft type and ramp area (gate groups)
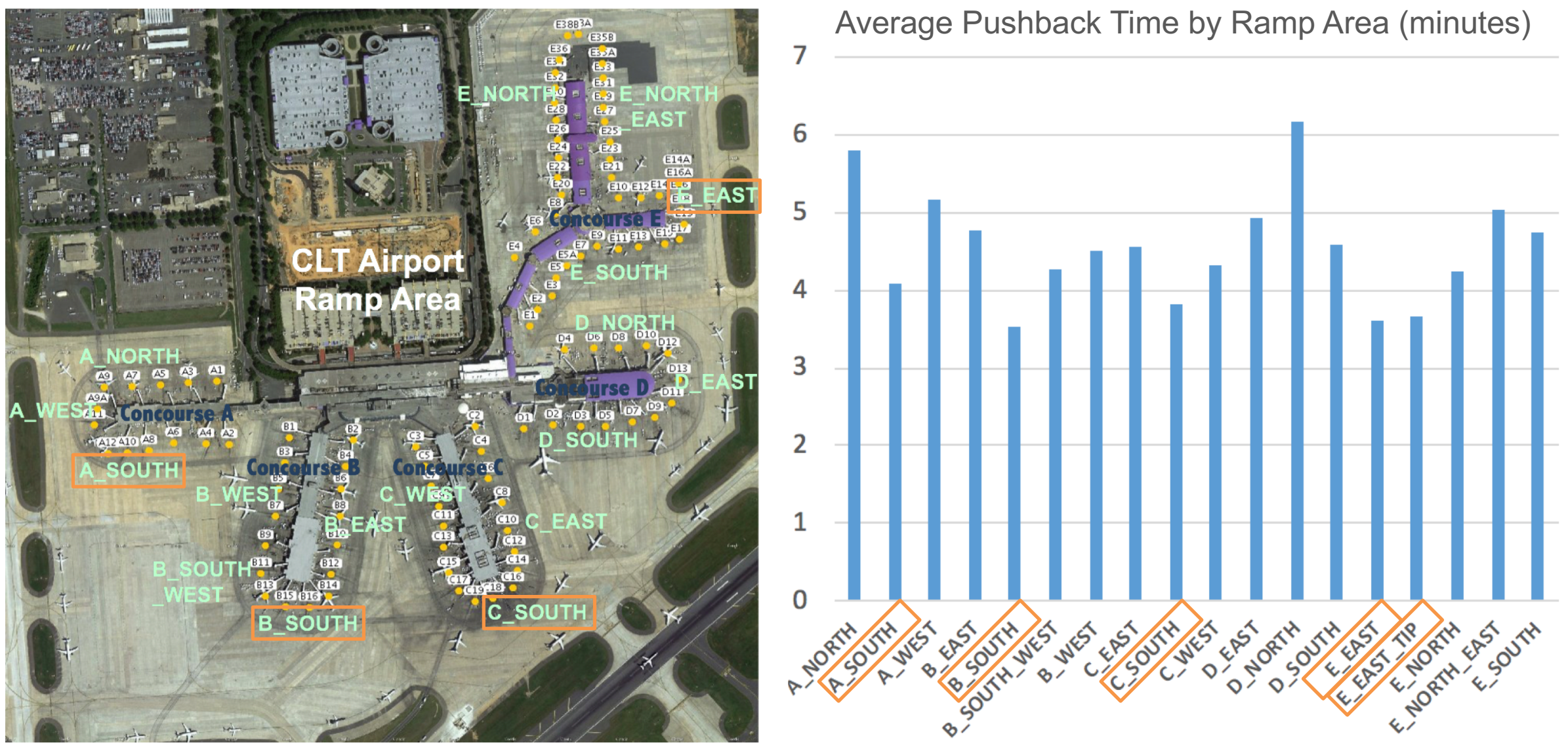
- Ramp taxi time depends on taxi distance and congestion

- Long taxi distance for westbound flights from concourse $E$

- Surface traffic congestion and complexity inside the ramp

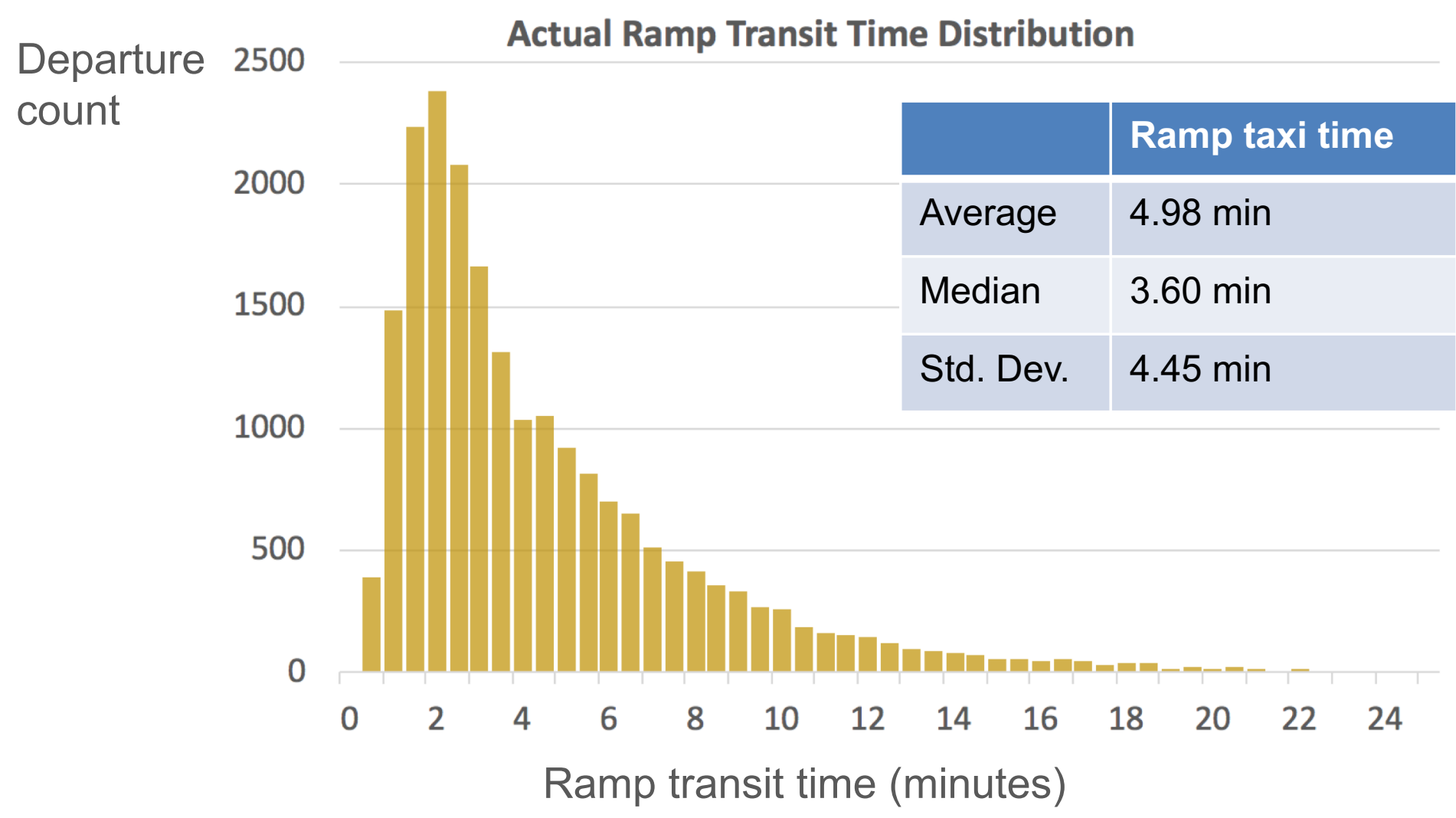




\section{ATDP}

Data-Driven Prediction Models for Pushback Time and Ramp Taxi Time 
- Decision Tree (DT) model based on historical data, using two main criteria

- Ramp area

- Aircraft type

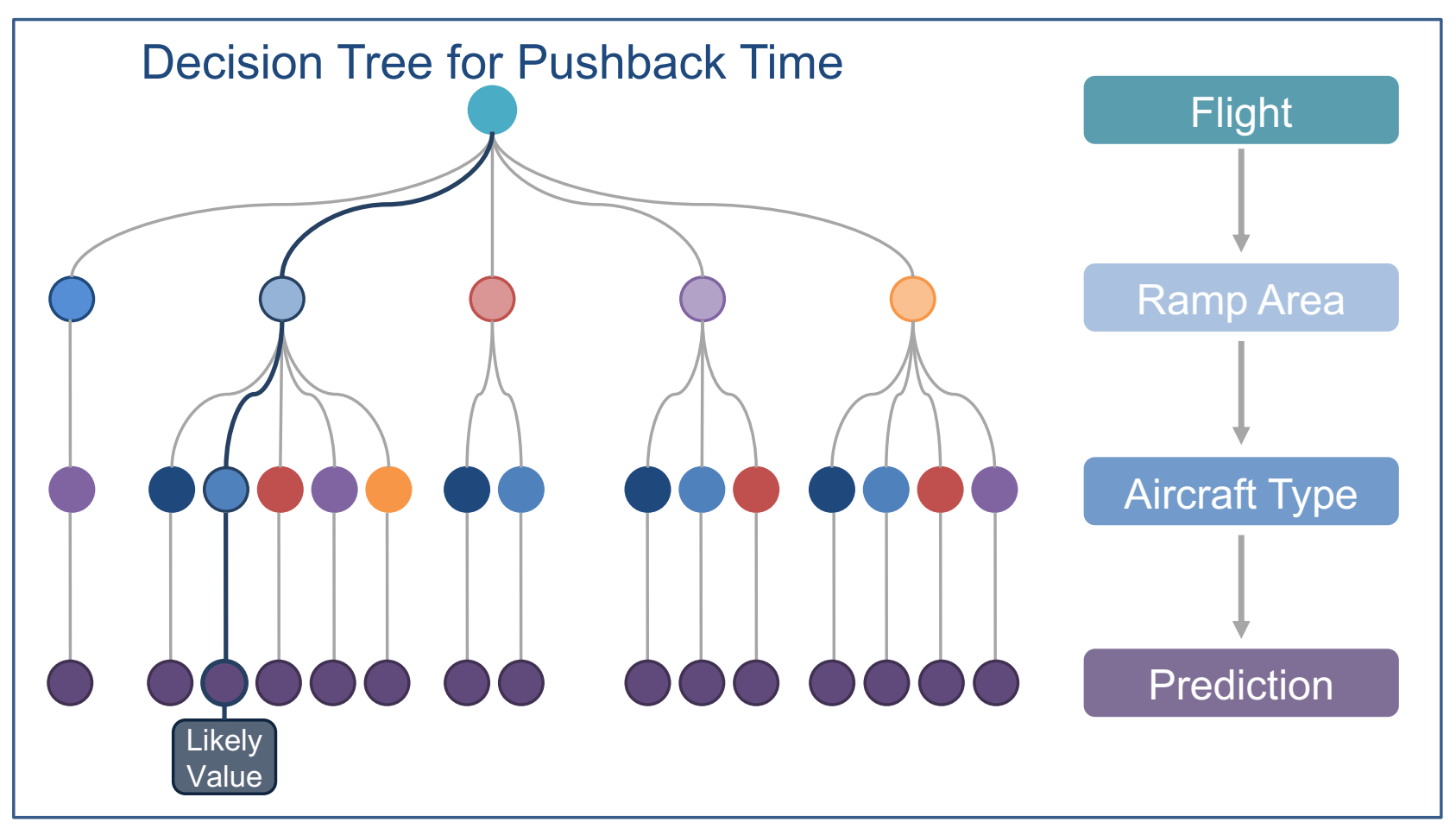


- Decision Tree (DT) model provides good prediction performance

- Prediction errors come from uncertainties in pushback processes

Departure 3500 count

Pushback Time Prediction Accuracy

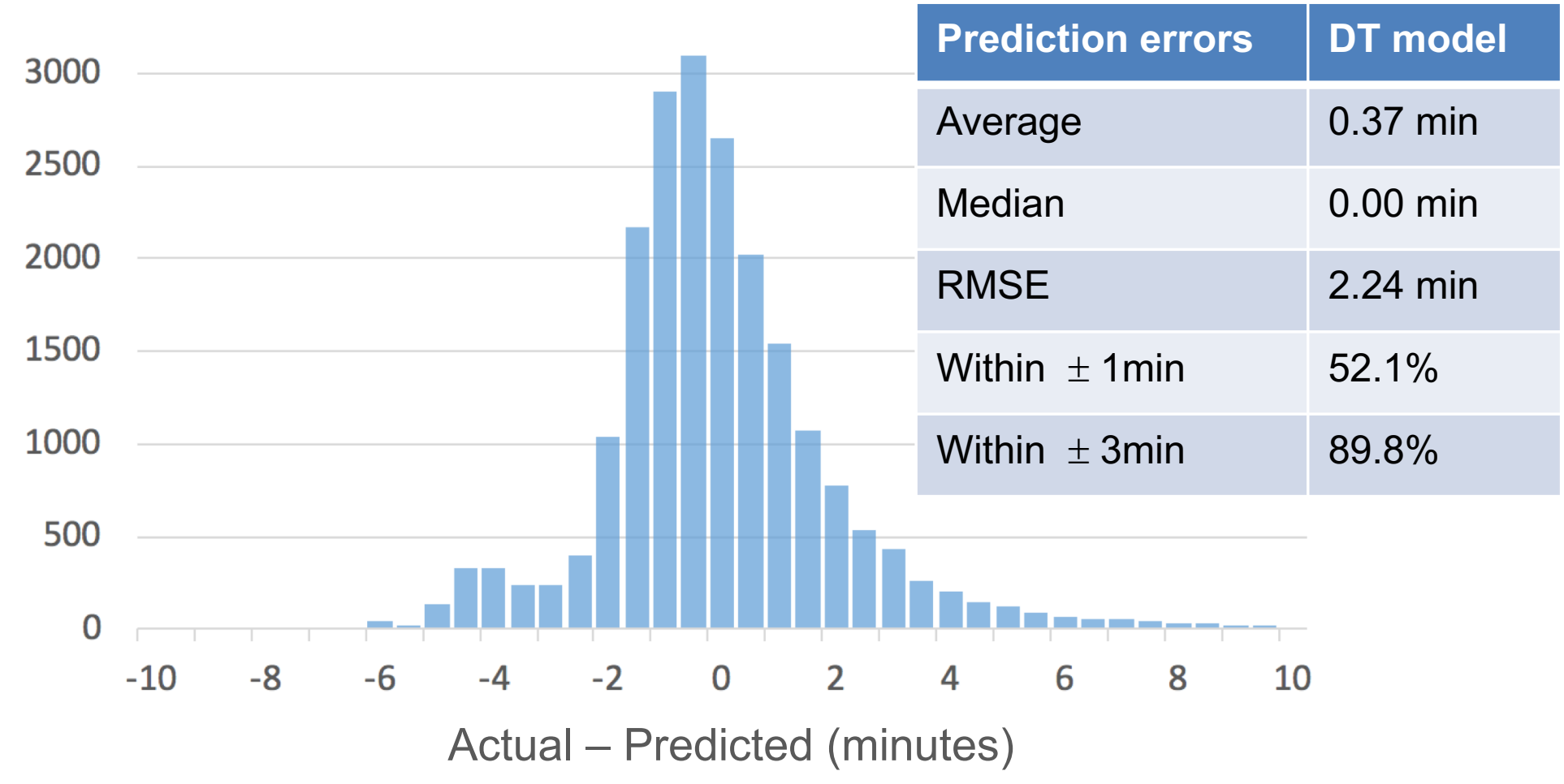




\section{Ramp Transit Time Prediction Using Data Driven (DD) Model}

- Assume a constant taxi speed in the ramp area

- Data Driven (DD) model calculates ramp transit times using a median ramp taxi speed (6.6knot) on the given taxi distance along standard taxi routes

Departure 3000

Ramp Transit Time Prediction Accuracy

count

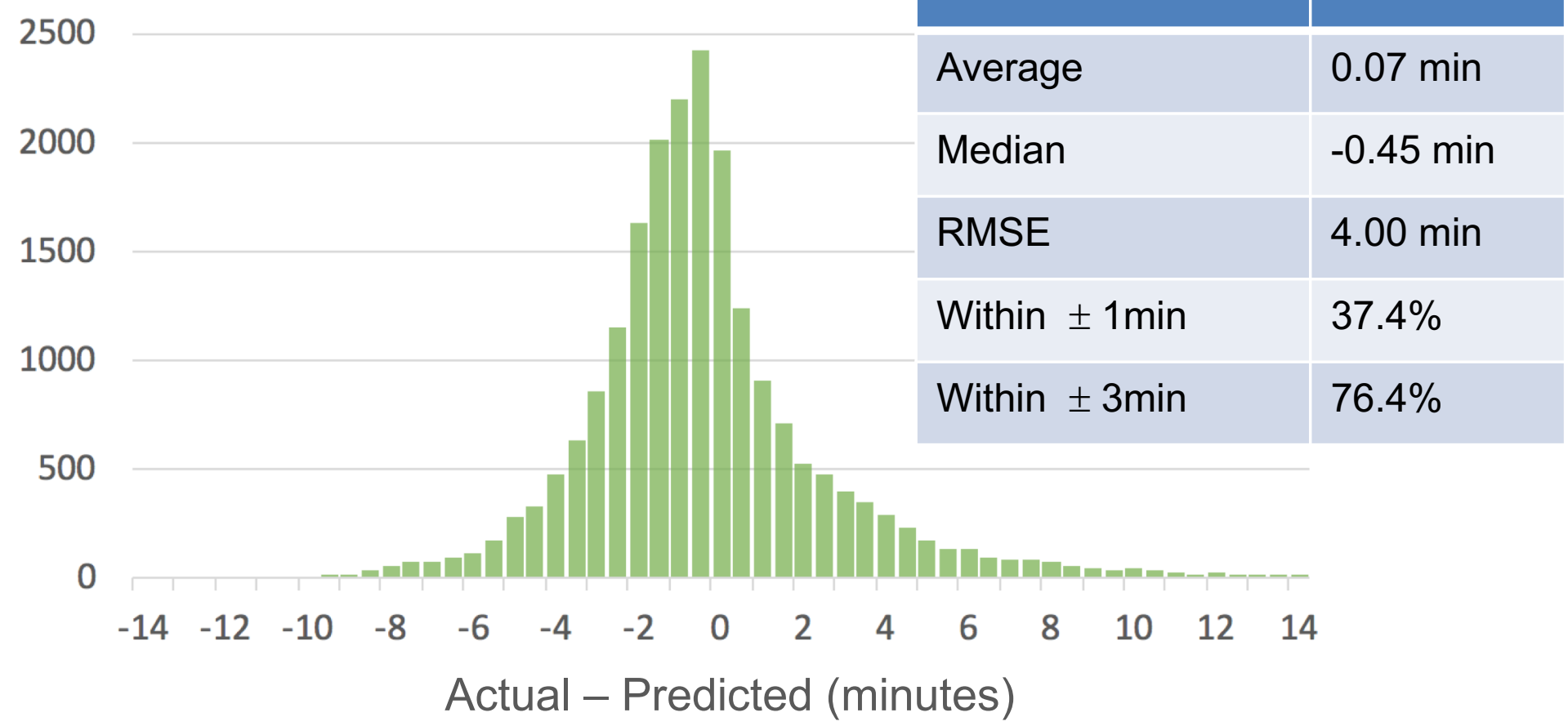




\section{ATD?}

Prediction Model Evaluation Using Machine Learning Algorithms 
- Six machine learning algorithms tested for comparison

- Linear Regression (LR)

- Support Vector Regression (SVR)

- Lasso linear regression (Lasso)

- $k$-Nearest Neighbors ( $k N N)$

- Random Forest (RF)

- Neural Networks (NN)

- Coded using sklearn (scikit-learn) library in Python

- Training and test dataset from the actual data at CLT in August 2018 


\section{ATD2 Features for Pushback Time Prediction}

- Ramp area (gate groups): 18 binary variables

- Carrier: 23 binary variables

- Aircraft type: 23 binary variables

- Pushback time of day (in hour)

- Gate conflict: binary

- Traffic Management Initiative restrictions: 2 binary variables

- Approval Request (APREQ)

- Expect Departure Clearance Times (EDCT)

$>$ Total 68 features defined and used for running machining learning algorithms 
Prediction Accuracy (Actual - Predicted) (in minutes)

\section{6}

4

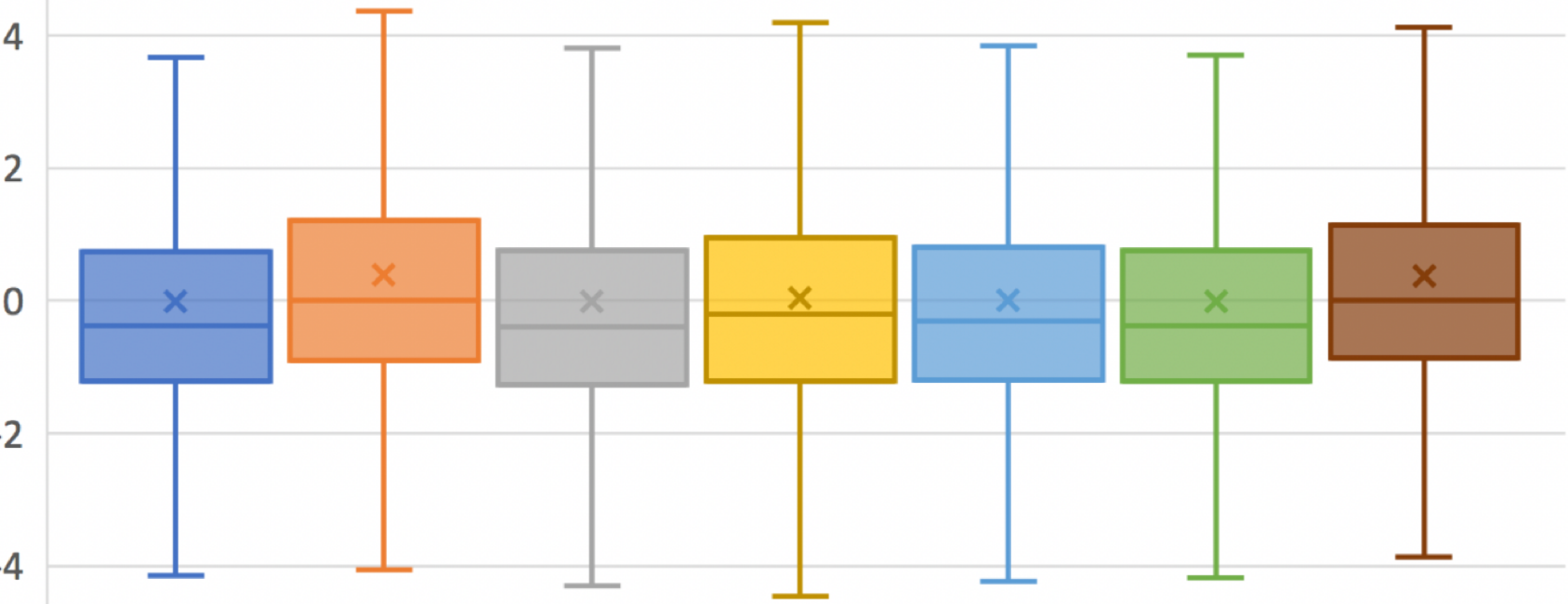

$-6$

\section{$\begin{array}{lllllll}\text { LR } & \text { SVR } & \text { Lasso } & k N N & \text { RF } & \text { NN } & \text { DT }\end{array}$}

\begin{tabular}{|r|c|c|c|c|c|c|c|}
\hline & LR & SVR & Lasso & kNN & RF & NN & DT \\
\hline Mean $(\min )$ & 0.00 & 0.39 & -0.01 & 0.05 & 0.00 & -0.01 & 0.37 \\
\hline RMSE $(\min )$ & 2.19 & 2.28 & 2.22 & 2.37 & 2.25 & 2.20 & 2.24 \\
\hline Within \pm 1 min & $47.9 \%$ & $49.4 \%$ & $45.4 \%$ & $45.8 \%$ & $47.9 \%$ & $47.4 \%$ & $52.1 \%$ \\
\hline Within \pm 3 min & $90.6 \%$ & $89.1 \%$ & $90.4 \%$ & $87.7 \%$ & $89.3 \%$ & $90.5 \%$ & $89.8 \%$ \\
\hline
\end{tabular}




\section{ATD2 Features for Ramp Transit Time Prediction}

- Ramp area (gate groups): 18 binary variables

- Spot: 25 binary variables

- Carrier: 23 binary variables

- Aircraft type: 23 binary variables

- Runway configuration: 3 binary variables

- Pushback time of day (in hour)

- Gate conflict, APREQ, EDCT: 3 binary variables

- Ramp taxi distance: a dominating factor for ramp transit time

- Number of departures taxiing in the ramp: to account for ramp congestion level

- Number of arrivals taxiing in the ramp: to account for ramp congestion level

$>$ Total 99 features defined and used for running machining learning algorithms 


\section{Prediction Accuracy Comparison}

Prediction Accuracy (Actual - Predicted) (in minutes)

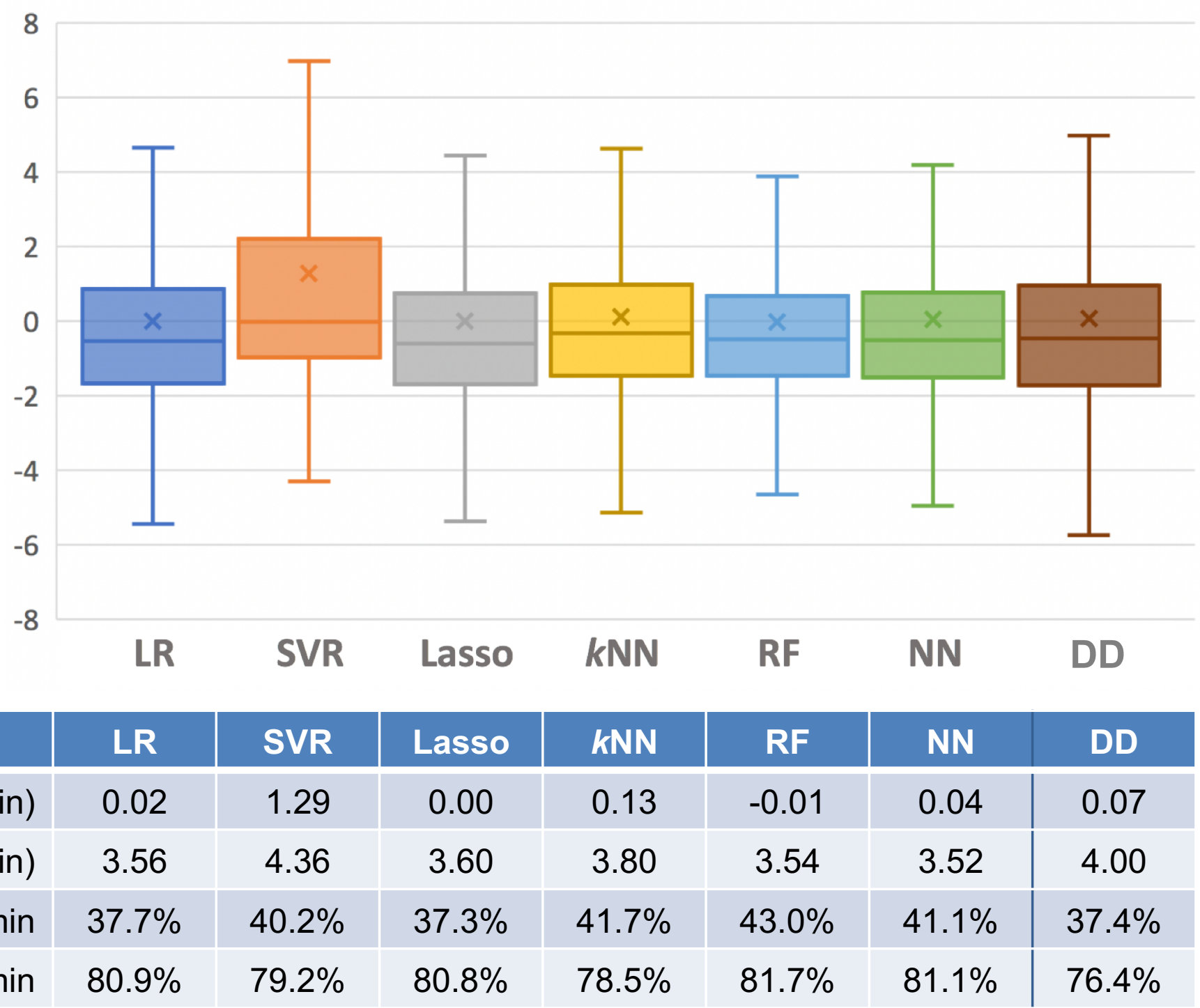


- Data-driven prediction models developed for pushback and ramp transit time prediction at CLT

- Pushback time prediction using a decision tree by ramp area and aircraft type

- Ramp transit time prediction based on the median taxi speed and the standard taxi distance

- Showed the similar prediction performance to machine learning algorithms

- These simple models can be

- Used in real-time operations systems, with acceptable prediction accuracy

- Applied to other airports, if high quality data are available 


\section{ATDP}

\section{Thank You}

hanbong.lee@nasa.gov 


\section{ATDD}

\section{Backup}


- To develop the Integrated Arrival, Departure, and Surface (IADS) traffic management capabilities

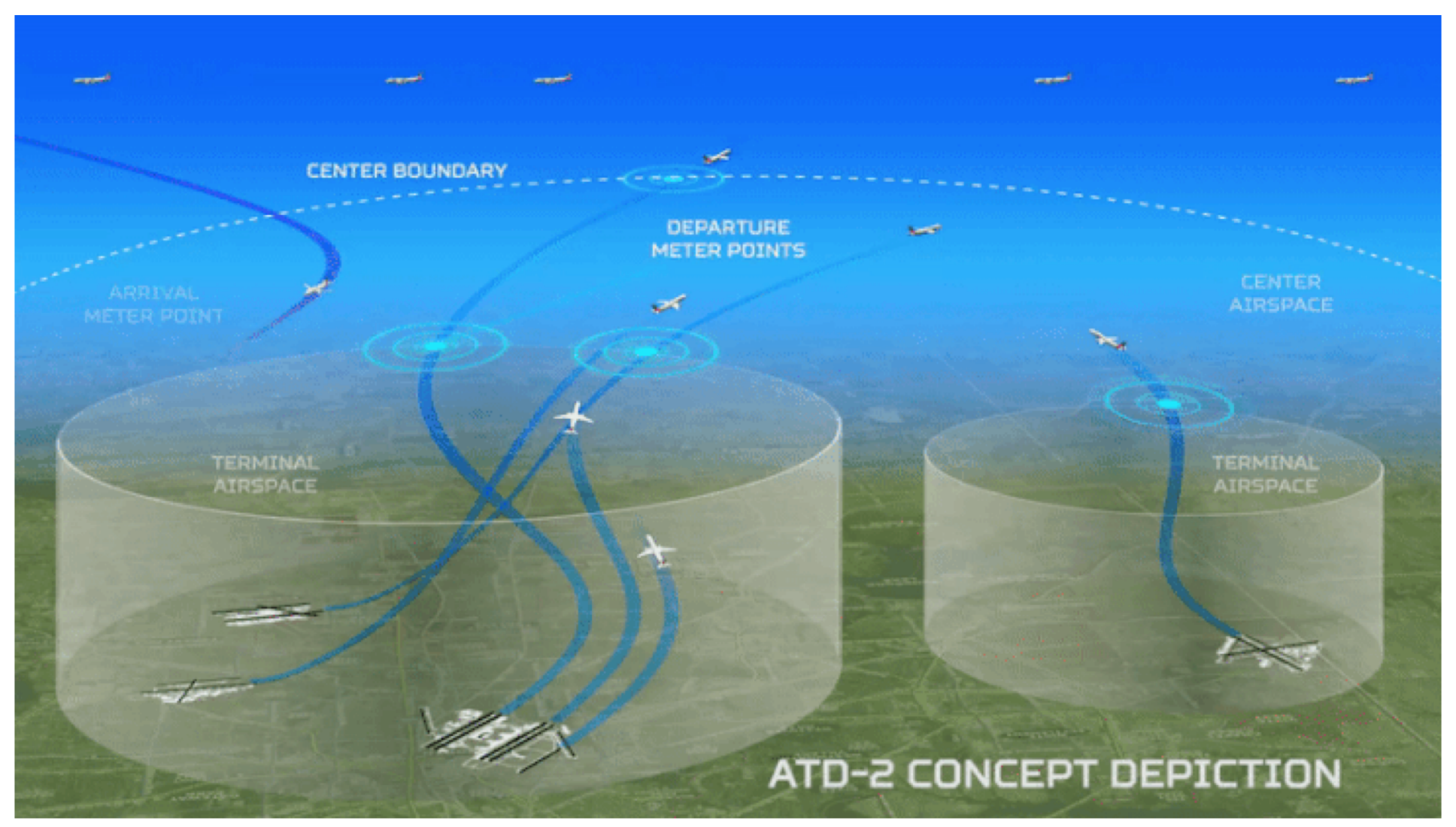


- Taxi time calculation for departures

Taxi-out time $=$ Pushback duration + Ramp transit time + AMA transit time
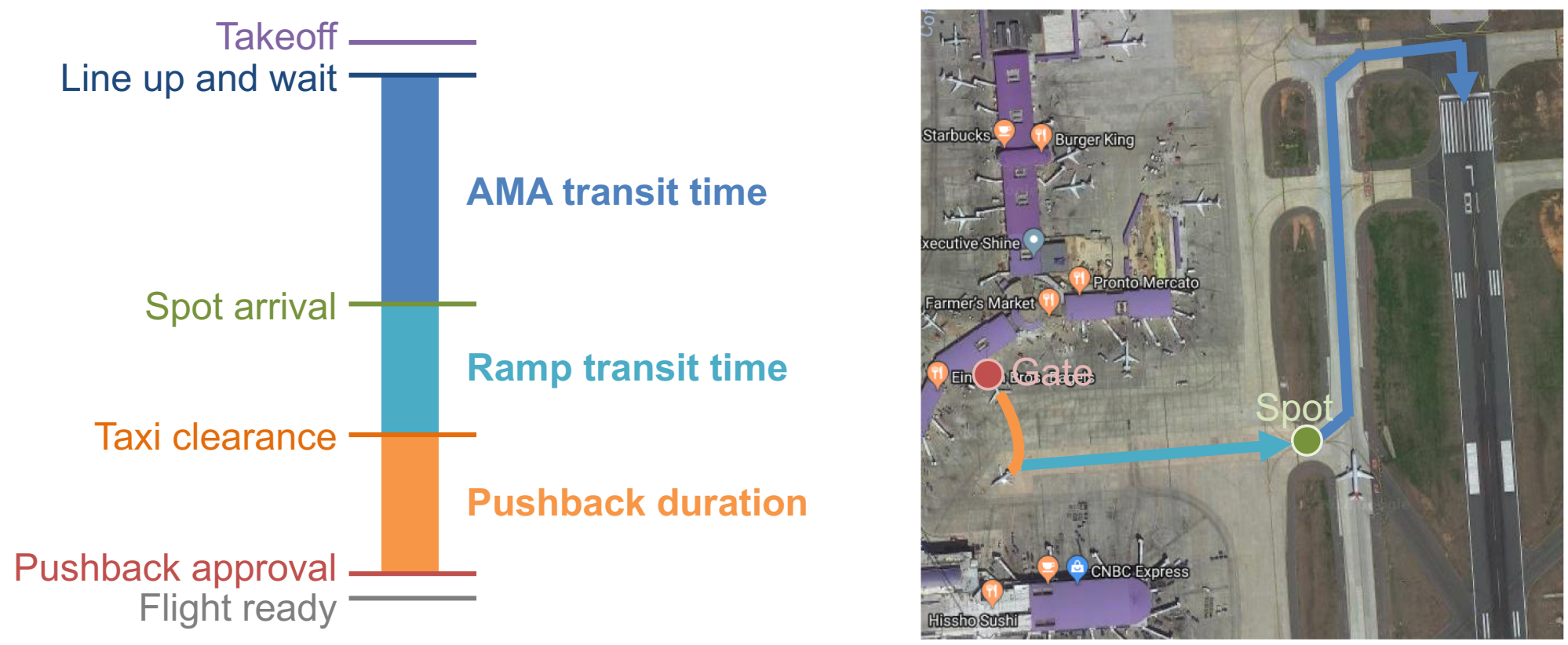

$>$ Lack of accurate data for pushback time and ramp transit time 
- Decision Tree (DT) model provides good prediction performance

- Default model using a median pushback time value (260sec) also shows similar results

Departure count 3500
Pushback Time Prediction Accuracy

a Decision Tree $\quad$ Default

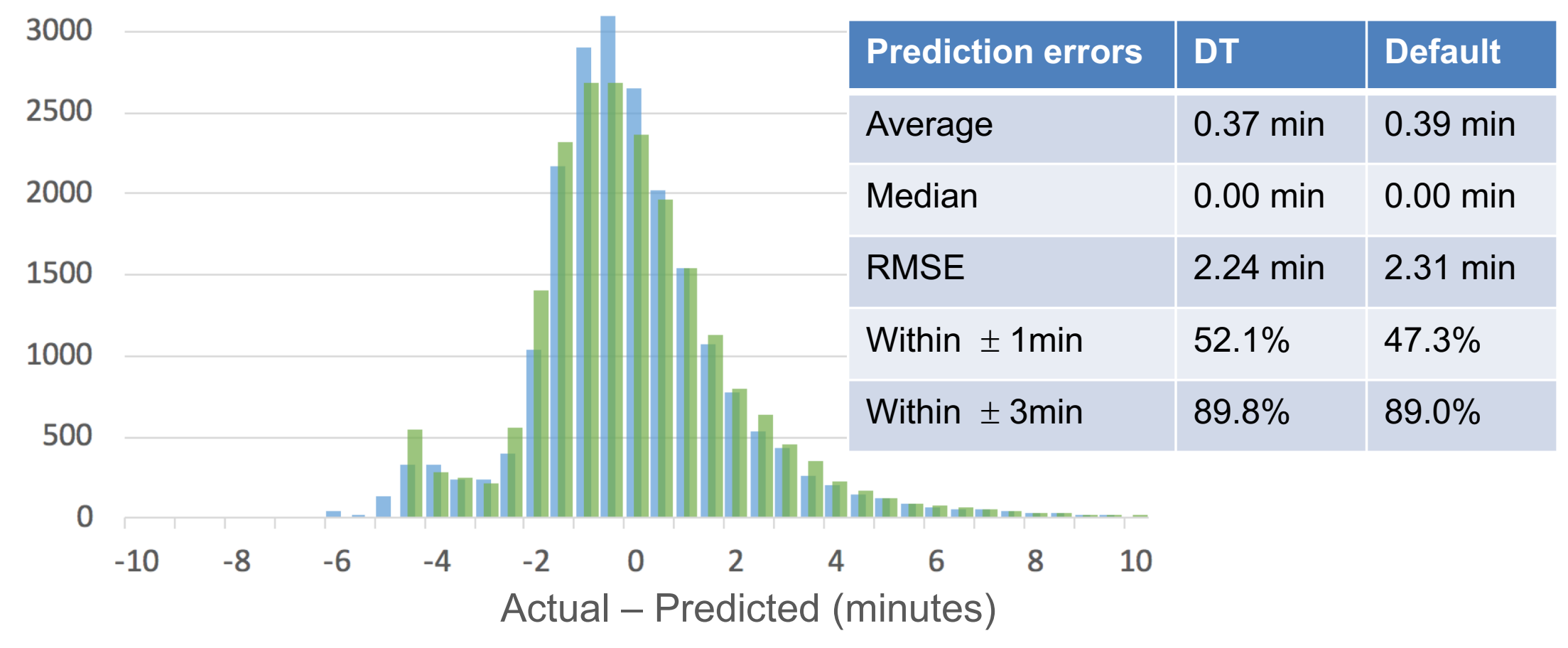




\section{ATD2 Ramp Taxi Time vs. Congestion Level}

- A weak positive correlation between ramp transit time and the number of departures and arrivals in the ramp
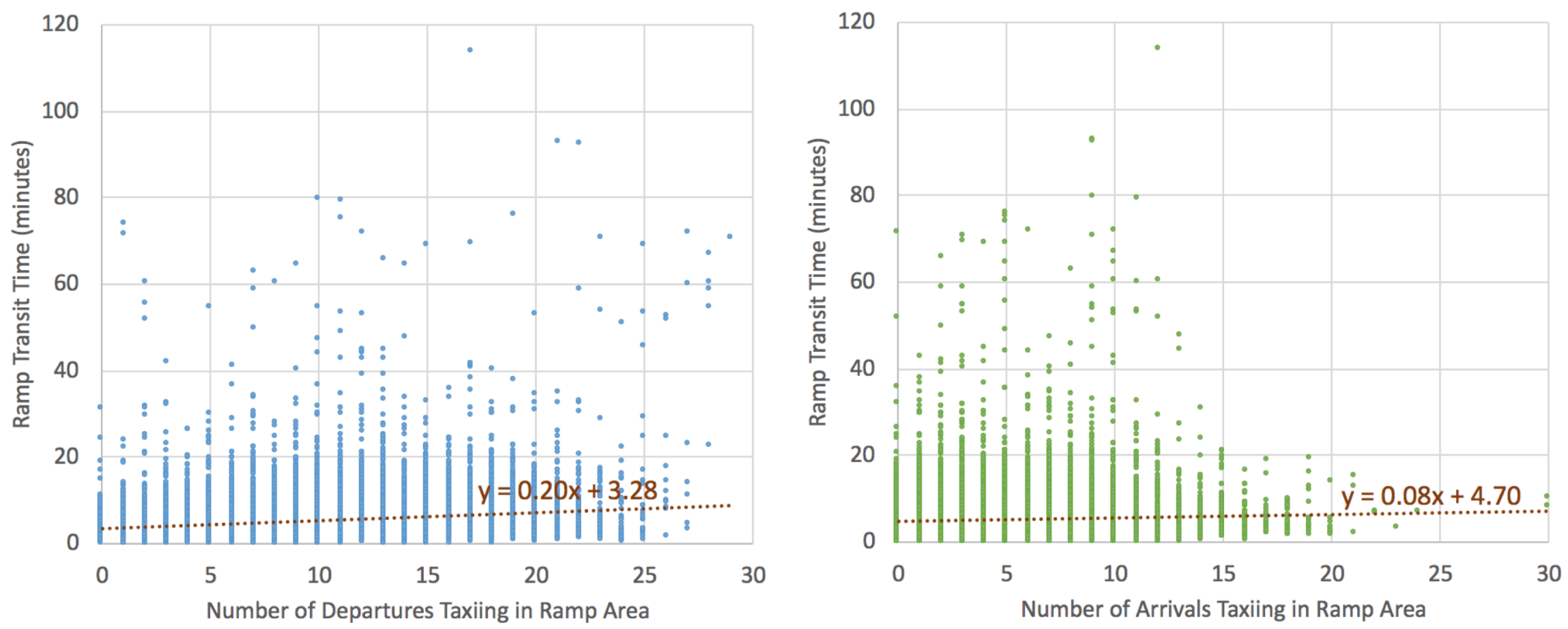